\title{
CONSIDERAÇÕES SOBRE A ESSÊNCIA DO PENSAR
}

\section{GLÓRIA MARIA FERREIRA RIBEIRO ${ }^{1}$}

RESUMO: Num escrito registrado entre 1944 e 45 intitulado Para discussão da serenidade, do filósofo alemão Martin Heidegger, temos retratada a conversa entre um pensador, um erudito e um professor. $\mathrm{O}$ tema da conversa é a questão sobre a essência do homem que acaba convergindo para a questão sobre a essência mesma do pensamento - que, tradicionalmente, é concebido como representação; isto é, como um querer. Contudo, no começo da conversa que se estabelece entre os três personagens, fica assentado que a essência do pensamento não se confunde com o pensamento mesmo. Sendo assim, se o pensamento é caracterizado como vontade, como querer, sua essência deve ser algo como o não-querer. Eis o problema posto, eis o nó da conversa. Porque esse não-querer não pode ser fruto da vontade (isto é, do próprio pensamento), enquanto essência do pensamento, o não-querer deve acontecer antes mesmo de qualquer vontade que queira dominar a realidade. É necessário colocar-se, então, na dimensão na qual o pensamento, compreendido como vontade, ainda não se determinou. E colocar-se nessa dimensão é estar entregue ao fenômeno da serenidade, que traduz a experiência mesma do pensar.

PALAVRAS-CHAVE: Pensar. Fundamento. Liberdade.

ABSTRACT: In an essay written about 1944 and 45 entitled Towards an explication of Gelassenheit: from a conversation on a country path about thinking, from German philosopher Martin Heidegger, we have depicted a conversation between a thinker, an erudite and a teacher. The theme of the conversation is the question about the essence of man which ends up converging to the question about the essence of thought itself - which, traditionally, is conceived as representation; or in other words, as a wanting. However, in the beginning of the conversation, which is established between the three characters, it is settled that the essence of thought cannot be mistaken with the thought itself. Therefore, if the thought is seen as will, as a wanting, its essence should be something like a non-wanting. Here is the stated the problem, here is the knot of the conversation. Because this non-wanting cannot be the outcome of will (which is the thinking itself) while essence of the thought, the non-wanting should happen even before any will that wishes to take over reality. Then, it is necessary to put oneself in a dimension which the thought is understood as a willing that hasn't been determined yet. And putting itself in this dimension is to be delivered to the phenomenon of releasement, which translates the same experience of thinking

KEYWORDS: Thinking. Foundation. Freedom.

\footnotetext{
${ }^{1}$ Professora titular do Departamento de Filosofia e Métodos da Universidade Federal de São João Del Rei (UFSJ). Possui doutorado e pós-doutorado em Filosofia Contemporânea pela Universidade Federal do Rio de Janeiro (UFRJ). E-mail: gloriamfr@yahoo.com.br.
} 


\section{I - À guisa de introdução ou sobre o homem e o tempo}

Martin Heidegger viveu no período compreendido entre os anos de 1889 e 1976. Sua obra Ser e tempo de 1927 exerceu e exerce forte influência no pensamento contemporâneo. Toda a obra de Heidegger se encontra voltada para a questão sobre o sentido do ser. Questão decisiva para o pensamento humano. Heidegger retoma, ou melhor, retorna a esta questão do ser, elegendo a existência humana e a linguagem como os âmbitos privilegiados para a sua elaboração. A primeira, por ser o homem o único existente capaz de pôr, para si mesmo, esta questão - na elaboração da questão sobre o sentido do ser, é dado ao homem compreender-se em sua verdade, ao mesmo tempo em que é tomado pela experiência da liberdade. A segunda, por ser a linguagem compreendida como a própria manifestação do ser na sua verdade. Para caracterizar o âmbito da existência humana, de forma a diferenciá-lo do modo de ser das outras coisas (que não possuem o modo de ser humano), Heidegger chama-o Dasein cuja estrutura fundamental é a de ser-no-mundo. Estrutura que evoca o nosso modo de ser cotidiano no qual nos vemos lançados no mundo em meio a entes, lidando com entes. Ente é tudo o que é. Seja a coisa na sua concretude, o nome, a imagem, o conceito, a ideia. Tudo isto, à medida que se encontra sob o jugo de uma determinação qualquer, é o que se chama ente. Desta forma, o homem é igualmente um ente. Contudo, o homem destaca-se dentre os demais entes por ser capaz de se perguntar sobre o seu ser, em meio à articulação da sua própria determinação ôntica que se dá, precisamente, na sua ocupação com os entes que lhe vem ao encontro no mundo. Este privilégio o transforma no "espaço" da diferença entre ser e ente. Mas, o que é o ser que caracteriza o homem e pelo qual ele se indaga no seio da sua lida com o mundo? Ser humano é ser finito, temporal. Entretanto, o tempo que se encontra no núcleo da finitude humana não se confunde com o tempo linear. O tempo é compreendido por Heidegger como a unidade extática do passado, presente e futuro. O caráter extático do tempo acha-se imbricado na estrutura da existência. Existir é eksistere: o ultrapassar, o sair de si (ek=ex) e insistir no mundo (sistere). O prefixo ex (ek), comum ao existir e ao êxtase do tempo, diz o mesmo movimento, de ultrapassagem e proveniência, que constitui o ser humano. Mas, o que é o tempo como esta unidade extática? Nesta compreensão do tempo os elementos temporais: passado, presente e futuro perdem a acepção tradicional que os concebem numa sucessão linear. O passado deixa de ser compreendido como os momentos da história do homem que passam e ficam para trás, cuja "presença" a memória é capaz de reter e evocar numa lembrança. O passado passa a ser o perdurar do vigor, da vigência do que foi no 
presente. O presente tido, tradicionalmente, como o elemento temporal privilegiado perde o privilégio. Se antes o presente é compreendido como o elemento temporal a partir do qual se dispõe, numa sucessão linear, o passado e o futuro, respectivamente, como o que vem antes e depois daquilo que se põe no momento presente; agora, este elemento temporal emerge como a atualidade do que é que, tocada pela vigência do que foi, abre uma "visão prospectiva" em direção ao futuro. O futuro, que na tradição é o que "ainda está por vir" e, que na linearidade representada pela sucessão temporal, mantém-se para fora do passado, permanecendo como uma "expectativa vazia" no presente, transforma-se no elemento temporal decisivo para compreender a existência humana. Assim experimentado, o futuro passa a ser denominado de porvir. O porvir permite ao homem a exposição $(e k)$ do que lhe é trazido (legado) pelo vigorar do passado, à medida que o passado, ao perpassar (insistir - sistere) (n)o presente, vê-se forçado, na tensão com o presente, a abrir-se em direção ao possível. Sendo assim, o porvir, por se encontrar referido intestinamente quer à atualidade do que é, quer ao vigorar do que foi, mantém o homem referido essencialmente à sua verdade mais íntima. E isto porque o homem compreendido em sua ek-sistência é essencialmente, poder-ser. Seja no "passado" ou no "presente" da história da sua humanidade, o homem vê-se lançado nas possibilidades do seu ser "futuro". Possibilidades que por estarem ligadas ao "passado", encontram-se previamente limitadas por este "vigorar do que foi" e por se relacionarem diretamente com o "presente", neste presente estão sempre sendo determinadas numa atualização. Donde se depreende que as possibilidades humanas são sempre limitadas, finitas por serem a expressão da unidade extática do tempo. O tempo compreendido como unidade extática das dimensões temporais do passado, presente e futuro, remete-nos para a articulação da história. Em Heidegger, este termo não se refere à ciência que, escrita pelos homens, relata e interpreta os fatos ocorridos no passado. Ciência que por se manter assim, enraizada no passado, aparta-se do presente, permanecendo fora de qualquer relação com o futuro. A história do ser, enquanto se articula na unidade extática do tempo, não se encontra assentada no passado, mas se encontra voltada para o futuro. Não fala do passado, como algo que se perfez - algo perfeito. Mas fala do passado como o êxtase que, vigendo e vigorando no presente, abre-se como o horizonte a ser ultrapassado no futuro. Nesta compreensão do tempo e da história, em que se realiza a existência humana, não é possível pensar num progresso linear dos acontecimentos históricos no tempo. O que seria considerado um acontecimento antiquado e ultrapassado, por se encontrar no início da história do pensamento ocidental, permanece vivo naquilo que nos é legado por este mesmo pensamento. Contudo, este legado não é uma mera repetição do 
passado. Mas, diz o modo como este passado é retomado e transformado no presente, de modo a ser novamente ultrapassado em direção ao futuro. O progresso do pensamento dar-seia assim num regresso: é somente indo ao encontro do passado no presente, que o futuro do pensamento pode se dar.

A história do ser, assim compreendida, fala-nos do tempo de maturação do ser; no qual a história dos homens transforma-se em história do mundo, na qual o ser é, concomitantemente, o ser de cada homem e o de toda a humanidade. Neste tempo de maturação, o ser retrai-se, ao realizar e tornar presente o projeto no qual se viu lançado pelo futuro vindo, nesta retração, a se tornar novamente passado. Passado este que, como pode se depreender, tem sempre as suas raízes no futuro.

Pois bem, o tempo de maturação do ser é aquele no qual o ser se torna pleno de si mesmo, como puro e simples poder-ser. Tornando-se, desta forma, o fundamento abissal do homem e do mundo. Por seu caráter temporal-extático, mais do que como fundamento, o ser se mostra como dinâmica de fundação, na qual o real está sempre vindo a ser. Com esta concepção de ser e de tempo, Heidegger lança por terra a compreensão da ontologia tradicional, segundo a qual o tempo é sempre compreendido linearmente e o ser é o fundamento substancial e estático do mundo. Em um escrito de 1928 intitulado Sobre a essência do fundamento, o ser, compreendido como dinâmica de fundação, se articula em três momentos, o erigir, o fundassentar e o fundamentar - que correspondem aos três êxtases temporais. $\mathrm{O}$ erigir corresponde ao êxtase do porvir, e acontece quando o ser, na realização da sua verdade, libera e ilumina todo um horizonte de possibilidades. O erigir se identifica com a estrutura da compreensão na qual o homem já sempre se encontra. Este momento diz tão somente a dinâmica de manifestação de mundo. Mundo é a totalidade de tudo o que é. Totalidade não como o somatório de todas as coisas, mas sim como o horizonte a partir do qual tudo vem a ser. Desde o qual, vem a ser tanto o homem como a sua circunstância cotidiana. Em outras palavras: mundo é a perspectiva a partir da qual tudo aparece (se determina). A tudo o que aparece, a tudo que é determinado, chama-se, genericamente, ente. Logo, o mundo, enquanto a perspectiva em função da qual todo o ente ganha consistência (se concretiza), não se confunde com ente algum. Mundo é, antes, a totalidade do ente: a condição de possibilidade de tudo o que aparece. Mundo é ser do ente. Por sua vez, o momento do fundassentar corresponde ao êxtase do vigor de ter sido - que nos lança numa disposição, que instaura o caráter fático do homem. Este momento é aquele no qual o ser se concretiza quando o homem se enraíza no mundo, numa ocupação junto aos entes, que neste mesmo mundo lhe vem ao 
encontro. Por sua vez, o fundamentar se encontra referido ao êxtase da atualidade - e diz a própria decadência do Dasein no mundo, à medida que se vê determinado pelo mundo, pelo ser dos entes. O fundamentar acontece quando, da articulação dos êxtases do vigor de ter sido e do porvir, brota a possibilidade do homem vir a compreender, a partir do seu enraizamento (expresso no fundassentar) numa ocupação junto aos entes no mundo, o caráter propriamente dito dos entes (que, juntamente com ele, foram liberados e projetados no erigir). É da intimidade, do "interior" da sua constituição existencial, que brota a possibilidade de o homem colocar, para si mesmo, a partir de si mesmo e do mundo, as questões relativas ao ser do ente ao qual o homem se encontra previamente referido, enquanto ente. A pergunta acerca do ser dos entes emerge daquilo que no homem é familiar. Contudo, esta familiaridade, esta proximidade que se verifica entre o ente humano e o ser, acaba por dissimular o que nesta questão deve ser decisivo. Não se trata de perguntar "O que é o ser?" Mas: "Como nos é possível compreendê-lo?" A pergunta “o que é o ser?” não pode ser respondida. O ser é puro e simples poder-ser, e, por conseguinte, puro movimento de auto-superação: dinâmica de transcendência. A cada época da história da sua maturação, o ser realiza (determina) esta ou aquela possibilidade que constitui o seu destino. Determinação que traz em si (em função do caráter extático do tempo que a ele pertence) a possibilidade da sua posterior superação. Pois bem, a tendência à dissimulação do que existe de essencial na questão acerca do ser, é inerente ao movimento no qual o ser se torna "fundamento" extático dos entes. E isto porque o ser imediatamente se retrai, no seu caráter dinâmico, quando libera (no erigir) todo um horizonte de possibilidades em que o homem se determina (no fundassentar) numa ocupação com os outros entes que, juntamente com ele, foram liberados em suas possibilidades de ser. Neste retraimento o ser se "concretiza" numa determinação, emergindo (no fundamentar) como o ser do ente. Ou seja, a "razão" de ser de tudo o que é. Por seu lado, a retração do movimento de fundação, "funda" as épocas da história: do tempo de maturação do ser. Estas "épocas" dizem o modo como o ser se diferencia de si mesmo - vindo a se determinar como lógos, energéia, idea, etc. - permanecendo, contudo, o mesmo à medida que, na expressão destas épocas, se mantém latente como o movimento de manifestação do ente em seu ser. Mas como nos é dado pensar o ser no seu caráter mais próprio?

\section{II - Sobre o pensar}

Num curso oferecido no semestre de inverno de 1951, na Universidade de Freiburg, 
Heidegger se pergunta, precisamente, sobre: o que significa pensar? Na elaboração dessa questão ele (Heidegger) retoma um fragmento atribuído a Anaxágoras (500 - 428 a. C.), segundo o qual: “Anaxágoras diz, portanto, que é o fato de possuir mãos que faz do homem a mais sábia das coisas vivas" (RAVEN, J. E, 1982, p.406). As mãos não se referem aos membros que seguem aos punhos e que se destinam, sobretudo, à preensão e ao tato. As mãos a que se refere Anaxágoras expressam antes o saber enquanto o comum pertencimento entre homem (ente humano) e ser. Isto porque antes de enunciar qualquer proposição ou juízo sobre o real, antes de se dispor às demonstrações silogísticas sobre a estrutura interna de um ser substancial; antes sequer de falar de forma objetiva, o homem pensa com as mãos porque, de imediato e na maioria das vezes, é com elas que ele concretiza o sentido do tempo. ${ }^{2}$ É nesse saber, oriundo do comum pertencimento de homem e ser, que se enraíza a técnica e a tecnologia. Mas para o que nos remete esse saber? Como nos é dado tematizá-lo?

$\mathrm{Na}$ sua analítica existencial, apresentada em Ser e tempo Heidegger retoma, através da análise da relação de co-pertencimento de homem e mundo, a simplicidade sempre em jogo na essência do pensar. Esse co-pertencimento é um fazer-se no mundo que se expressa sempre numa tarefa $(\text { Hand-Werk })^{3}$ - na qual se põem em pauta tanto uma ocupação como uma preocupação com os demais entes. Nessa tarefa se determina, numa disposição, a compreensão que o homem possui de ser. A compreensão, determinada por uma disposição, se expressa sempre na forma de uma interpretação que não se confunde com nenhuma exegese de textos teóricos ou literários, mas é antes, o modo como o ser (aberto na compreensão e determinado pela disposição) ganha "corpo", "forma" como isto ou aquilo, no desempenho de uma ocupação. Essa ocupação, na qual o homem já sempre se compreende determinado em seu ser e que define, por sua vez, a existência humana como tal, expressa concomitantemente, a própria essência do homem. O ser humano está assim determinado por uma compreensão de ser. Poderíamos mesmo dizer que aqui, ser (humano) e pensar (o ser) são o mesmo. Contudo,

\footnotetext{
2 Acerca dessa relação nos fala um poema de Rainer Maria Rilke (1875-1926), poeta com quem Heidegger estabelece diálogo (em alguns dos seus escritos) acerca da poesia e do seu dizer. O poema para nós em questão encontra-se no "Livro de horas" (Das Stundenbuch) escrito entre os anos de 1889 e 1903. Nele Rilke nos fala: "Todos os que movimentam as mãos \não no tempo, mas na cidade pobre; \odos os que põem as mãos de leve n'algum lugar, distante dos caminhos, $\backslash$ e mal chegam ainda a ter um nome: $\backslash$ Todos falam de ti, benção diurna, $\backslash$ e de uma folha com doçura dizem $\backslash O$ que no fundo existe é apenas prece, $\backslash$ e assim as mãos que nos são consagradas $\backslash$ coisa alguma criam que não implore; \se antes alguma pintava ou ceifava, \já na circunscrição das ferramentas $\backslash$ era a devoção que se desdobrava. $\backslash$ O tempo é uma mão de muitas formas. $\backslash$ Muitas vezes no tempo nósouvimos o antigo e o eterno se fazendo; \e sabemos que um deus nos envolvia". Tradução de Geir Campos. (RILKE, 1993, p.58).

${ }^{3}$ Segundo o Professor Emmanuel Carneiro Leão, "Tarefa = Hand-Werk: tarefa não é uma boa tradução de HandWerk, se for entendida em sua acepção corrente. Pois Hand-Werk não é só tomado aqui no sentido de uma composição de Hand (mão) e Werk (obra), mas alude à Essência originária da obra da mão, que não reside na materialidade e no efeito de sua produção e sim na consumação de uma referência à verdade do ser". In: HEIDEGGER, M., 1967, p. 70-71.
} 
essa mesmidade não se confunde com uma identidade absoluta entre o ser e o ente, no qual o pensamento acontece. Pensar é o mesmo que ser à medida que pensar é a própria experiência (de compreensão) de ser que se traduz sempre e a cada vez numa tarefa na qual a própria existência humana acontece. Tarefa que expressa o sentido autêntico da linguagem como a liberação e a concretização de um horizonte de significância no qual o mundo se plasma como a nossa circunstância mais próxima. Por conseguinte, ser e pensar são o mesmo, nessa experiência autêntica da linguagem - na qual o ser é acolhidoไrecolhido numa tarefa. Contudo, essa experiência só se deixa pressentir como uma negação de todo dizer objetivo - à medida que se mantém indiferente à vontade do sujeito cognoscente, justamente, porque se encontra aquém dessa vontade. É a experiência do nada (querer) que se põe no espaço da diferença, do não entre o ente (o ser humano) e o ser (enquanto tal).

Pois bem, para Heidegger, a época da história do ser, que se traduz no esvaziamento das relações que o homem estabelece com o mundo, expressa o limite, o limiar no qual se abre, para esse mesmo homem, a possibilidade suprema de experienciar o sentido mais radical de ser. Ou seja, nessa época da história do ser, em que o perigo de uma "agressão contra a vida e o ser do homem" (HEIDEGGER, 1976, p.143), trazido pela tecnologia, nos ronda tão de perto, é que se abre a possibilidade de experienciarmos a liberdade a que pertencemos. É Heidegger quem, retomando um verso de Hölderlin (1770-1843), nos diz: “onde, porém, anda o perigo \Também anda um salvador" (HÖLDERLIN, 1994, p.163). Isso se explica porque, consoante Heidegger, "o não niilificante do nada se une ao não niilificante da diferença ontológica, se unem no essenciante do ser dos entes" (HEIDEGGER, 1988, p. 8.). Isto é: se unem onde o ser se faz e se mantém como o fundamento dos entes. Por conseguinte, quando o ser é mais propriamente compreendido na sua identidade com o ente - na forma do fundamento - é que se nos torna possível pensar a diferença que se estabelece entre um e outro. Diferença que se põe como o espaço do jogo do tempo em que a própria liberdade se constitui.

\section{III - O pensamento que calcula}

Por sua vez, é com o pensamento de Descartes que a identidade entre ser e ente é radicalizada. Radicalização na qual essa identidade alcança a sua plenitude, o seu fim. Mas, em que consiste esse pensamento? Como o novo começo do pensamento, que se descobre com Descartes, implica no fim da própria filosofia? 
A posição metafísica fundamental de Descartes foi trazida pela metafísica de Platão e Aristóteles. Ela se move, malgrado o novo começo, no horizonte da mesma questão: o que é o ente? Que essa questão não se encontre nas Meditações de Descartes não prova nada, senão que a modificação essencial da resposta dada determina já a nova posição fundamental. Somente a acepção cartesiana do ente e da verdade criou a condição de possibilidade de uma teoria do conhecimento ou de uma metafísica do conhecimento (HEIDEGGER, M., 1976, p.143).

Segundo o professor Raul Landim, no pensamento de Descartes, o homem é compreendido como "o sujeito que permanece idêntico a si mesmo na diversidade dos seus atos" (LANDIM, 1992, p. 38) e cujo principal atributo é o pensamento. Ou melhor: o pensamento é o responsável, a causa, a razão que unifica a diversidade dos atos do sujeito. O que equivale a dizer que a existência do sujeito, o que ele é, necessária e indubitavelmente, se define pelo próprio ato de pensar. Assim, a cada vez que o sujeito se realiza em seu ser, isto é, a cada vez que pensa, qualquer que seja o conteúdo dos seus pensamentos, de imediato e necessariamente, o sujeito se torna consciente de si mesmo à medida que se re-apresenta para si mesmo, desde aquilo que se faz para ele objeto dos seus pensamentos. A essência do pensar passa a ser, então, concebida como a subjetividade do sujeito à medida que o pensamento se transforma numa representação desse mesmo sujeito. "Representar significa aqui: à partir de si, pôr alguma coisa diante de si, em se assegurando, em confirmando e garantindo o assim fixado" (HEIDEGGER, 1976, p.143). O assegurar, confirmar e garantir implícitos na representação, nos remetem para a evidência com que o ser se apresenta para o pensamento. Evidência que traduz a clareza e distinção com que o ser se apresenta para o sujeito numa intuição - na qual esse mesmo sujeito, de imediato, apreende a si mesmo, tornando-se indubitavelmente presente para si mesmo. É dessa evidência que advém a certeza em que se deve basear a relação que o sujeito estabelece com o mundo, que a ele se contrapõe como o seu objeto de conhecimento.

\footnotetext{
A certeza fundamental é representável e representada à todo instante, o indubitável me cogitare $=$ me esse . Eis a equação fundamental de todos os cálculos da representação, se assegurando e se garantindo ela mesma. Nessa certeza fundamental, o homem pode estar seguro que ele é - enquanto representante de toda representação, e assim, enquanto dimensão de todo ser - representante, portanto, de toda certeza e verdade (HEIDEGGER, 1980, p.141).
}

Certeza que faz desse conhecimento uma relação de apoderamento em que tudo passa a ser dissolvido numa relação de identidade. Ou melhor, nessa relação está em jogo a identidade e a diferença entre os termos da relação. Identidade do sujeito consigo mesmo e a diferença entre ele (sujeito) e o mundo (a totalidade das coisas existentes) que, ao se contrapor ao 
sujeito se apresenta, desde a perspectiva dessa contraposição, como objeto. É essa identidade que se mantém quando o real se apresenta para o sujeito, ou seja, é porque o homem consegue se manter essencialmente referido a si mesmo, que ele consegue perceber-se em sua diferença com o mundo. Poderíamos mesmo dizer que, essa certeza em que se traduz a evidência dessa auto-referência do sujeito a si mesmo, expressa o novo começo, o novo phatos da filosofia, consoante Heidegger: "A disposição afetiva da confiança na absoluta certeza do conhecimento, a cada vez acessível permanece o phatos e com isso a arché da filosofia moderna" (HEIDEGGER, 1978, p. 220). Assim, na época moderna, o espanto do filósofo diante do caráter determinado do ser (espanto diante do fato de as coisas serem o que elas são) se dilui na disposição da certeza à medida que essa determinação de ser ganha clareza e distinção. Ou seja, o espanto se dilui na certeza da proveniência dessa determinação de ser, que não é outra que a própria subjetividade do sujeito. A certeza do sujeito, eis o novo começo da filosofia que se abre no pensamento moderno. Porém, a novidade desse novo começo consiste, precisamente, na clareza e distinção com que agora se nos apresenta aquilo que, desde o princípio da filosofia, nos espantava. Pois bem, a certeza que assim se põe como o novo começo da filosofia, nada mais é do que a tradução da (auto) referência do sujeito (a si mesmo). Certeza que expressa aquilo que no pensamento metafísico existe de essencial, ou seja, o querer a si mesmo. Ou melhor: esse querer, essa vontade de (auto) apoderamento é que mantém o sujeito referido a si mesmo. Vontade em que se baseia a relação de conhecimento que o homem estabelece com o mundo. Isso equivale dizer que, essa vontade de querer é a mola que move o conhecimento baseado nessa re-apresentação do sujeito para si mesmo, ou seja, baseado no pensamento compreendido como representação. Representação que, ao expressar esse querer a si mesmo da subjetividade, assume a forma de um pensamento que tudo mede e calcula, no qual o sujeito do conhecimento passa a ser a medida de todas as coisas, à medida que tudo se mantém a ele referido. Ora, quando o mundo (o objeto) se apresenta ao sujeito o que se põe em evidência é esse querer, essa vontade. Sendo assim, o caráter objetivo do mundo emerge desde a própria subjetividade (do sujeito). O mundo ao ser concebido dessa forma passa a ser controlado pela vontade de (auto) apoderamento do sujeito. É essa vontade de querer que se encontra na raiz do comportamento teórico que orienta o sujeito na sua relação com o objeto e, que se distancia do comportamento que o homem estabelece cotidianamente com o mundo. O comportamento teórico se originaria de uma visão clara e distinta que o sujeito possui de si mesmo. Contudo, o si mesmo em que se constitui a identidade do sujeito, como vimos, não considera o mundo, mas, somente o sujeito - porque o 
mundo se apresenta para ele (sujeito) como uma re-apresentação de si mesmo. Essa visão teórica, por se manter referida apenas ao sujeito, acaba por romper o sentido mais original da relação que se estabelece entre homem\mundo. Desde essa ruptura é que se constroem esquemas nos quais se projeta, se calcula e se manipula o mundo que, reduzido ao pensamento do sujeito, acaba por lhe servir de objeto. Assim, a referência essencial do homem ao ser, que se revela sempre e a cada vez que ele se ocupa com o mundo, se retrai (se nega) radicalmente nesse comportamento teórico em que se traduz essa época da história do ser. Retração (negação) que se mostra no fenômeno da vontade de querer já sempre em jogo na estrutura da subjetividade, em que a relação sujeitolobjeto encontra seu fundamento. Ora, se a vontade de querer traduz a retração - na qual se nega a referência essencial homem $\backslash$ mundo -, e se essa retração radical é o lugar no qual se reúne o todo dessa história em sua extrema possibilidade (lugar que para Heidegger se expressa como o fim de algo), teríamos que, a vontade de querer é o lugar em que a metafísica (como a história do esquecimento de ser), chega ao fim.

Em um escrito, elaborado para servir como comentário a um discurso do ano de 1959, intitulado Da serenidade, proferido por Heidegger em sua terra natal por ocasião do aniversário de cem anos da morte do compositor Conradin Kreutzer, Heidegger se dispõe a meditar, precisamente, sobre a essência desse pensamento que tudo mede e calcula. Ora, sendo esse pensamento caracterizado como vontade de querer, Heidegger, ao se perguntar desde onde essa vontade vigora - isto é, ao perguntar onde reside a sua essência -, chega à conclusão que, essa essência, esse vigor não pode ser ele mesmo caracterizado como vontade, como um querer. Emergindo, então, como um não-querer. Contudo, essa negação não se baseia numa operação do entendimento, à medida que se encontra aquém de qualquer operação da razão humana. O não-querer que deve caracterizar a essência original do pensamento (que tudo mede e calcula) não é, portanto, algo que esteja nas mãos do sujeito. Segundo Heidegger, o não-querer tem de nos ser concedido e, por ser assim, é algo que se nos mostra de todo desabitual - à medida que nos habituamos, enquanto o sujeito do conhecimento, a sermos aqueles que detêm o poder de planejar e calcular, e de assim conferir medida a tudo o que é.

\section{IV-Sobre a essência do pensar e o salto}

Ora, se retomarmos o problema do conhecimento desde a analítica existencial empreendida 
por Heidegger em Ser e tempo, teríamos que todo e qualquer conhecimento acontece à medida que o Dasein se projeta no mundo (no poder ser que caracteriza as possibilidades do homem). Por conseguinte, perguntar sobre o não-querer enquanto a essência do pensamento incidiria, mais radicalmente, sobre a origem desse horizonte de possibilidades, desde o qual, algo assim como o conhecimento, acontece. É a origem desse horizonte de possibilidades de ser que, mais propriamente, se caracterizada como um não-querer. Horizonte no qual o Dasein continuamente se projeta vindo a se singularizar - como um si-mesmo. Assim, a pergunta sobre a essência do pensamento, ao recair sobre a origem do horizonte de possibilidades do Dasein, incide, numa última instância, na questão sobre a essência que diz o que o homem é, o que é e como é. Isso equivale a perguntar sobre a abertura desde a qual é liberado esse horizonte e, consequentemente, sobre o mundo - no qual o Dasein se singulariza. Desta forma, o não-querer se mostra como o fenômeno que libera tanto o ser como o não-ser que se põe no horizonte de possibilidades do Dasein. O não-querer se constitui assim como o caminho de volta, o retorno para aquilo a que o Dasein pertence mais propriamente - o retorno para o lugar onde ele se enraíza. Retorno que lhe permite compreender o destino desde o qual a sua história se articula. Esse retorno expressa o sentido mais próprio da superação intentada pelo pensamento de Heidegger.

Portanto, a superação do pensamento que se diluiu nas ciências dessa época da história do ser marcada pela tecnologia, não possui aqui o sentido de sobrepujar, de ir além de, estar acima desse pensamento. A superação, tal como nos é dado compreender pelo pensamento de Heidegger, tem, antes, o sentido de um ir ao fundo de, se dispor para o âmbito no qual se encontra enraizado esse tipo de pensamento. Superação que, portanto, somente se torna possível à medida que lhe dizemos um "sim" e um "não".

Nós dizemos "sim" a este pensamento - o afirmamos - à medida que nos propomos meditar sobre a sua essência. E nós lhe dizemos "não" enquanto o impedimos de nos reter inteiros sob o seu domínio e, assim, de falsear, obscurecer e finalmente esvaziar o nosso ser. ${ }^{4} \mathrm{Um}$ velho termo se oferece a nós para designar esta atitude do "sim" e do "não" ditos em conjunto ao mundo técnico: é o termo Gelassenheit, "serenidade", igualdade de alma. (HEIDEGGER, 1976, p.145).

A conferência intitulada $O$ princípio de razão, pronunciada por Heidegger na ocasião do quinquagésimo jubileu da Universidade de Freiburg no ano de 1957, nos fala da experiência do pensar, ao falar da correspondência entre o homem e o ser como um "comum-pertencer". Contudo, como já dissemos anteriormente, segundo Heidegger "nós não penetramos ainda no

\footnotetext{
${ }^{4}$ Cf. HEIDEGGER, 1976, p.146.
} 
comum-pertencer" (HEIDEGGER, 1978, p. 381). Somente quando nos distanciarmos do pensamento que calcula é que iremos aí penetrar. Esse "distanciar", como vimos, implica em um dizer "não" à pretensão desse pensamento que tudo quer regular através do cálculo. Dizer "não" que já é sempre um dizer "sim" àquilo que nesse pensamento existe de essencial. Ora, ao nos distanciarmos do pensamento da técnica nós nos distanciamos, concomitantemente, do ser compreendido como fundamento do ente. Esse distanciar caracteriza a experiência do pensar como liberdade e acontece num salto:

Para onde salta o salto, se se distancia do fundamento? Salta num abismo (sem fundamento)? Sim, enquanto apenas representarmos o salto e isso no horizonte do pensamento metafísico. Não, enquanto saltamos e nos abandonamos. Para onde? Para lá onde já fomos admitidos: ao pertencer ao ser (HEIDEGGER, 1976, p.145).

Saltar no abismo é saltar no "espaço" entre ser e fundamento. Mas como ser e fundamento se pertencem e, de que modo desse pertencimento já sempre faz parte uma diferença? Como foi visto até aqui, considerados desde a perspectiva dos entes, ser e fundamento são o mesmo. Ou melhor: desde os entes, o ser se mostra essencialmente como fundamento. Ora, a diferença entre ser e fundamento reside, precisamente, naquilo que há de essencial no fundamento, ou seja, na essência do fundamento. Pois bem, por ser fundamento dos entes, o ser nele mesmo, não pode ter um fundamento que o fundamente. Em Aristóteles se verifica essa mesma colocação acerca da impossibilidade de que exista um fundamento que fundamente o próprio fundamento. Ao se referir ao Theós como o fim último para o qual tende todas as coisas, Aristóteles o concebe como o fundamento (ser) supremo que deverá pôr fim à cadeia das causas do real. Para além do Théos nada pode ser posto, caso contrário a cadeia das causas iria ao infinito. Essa causa (fundamento) final é concebida pelo estagirita como ato puro destituído de potência (de toda possibilidade de poder-ser para fora de si mesmo). O Théos é a expressão suprema da necessidade de ser. Contudo, Aristóteles não se interroga sobre a essência desse Théos capaz de ordenar o mundo à medida que causa tanto o movimento de atualização das substâncias compostas como, igualmente, põe fim a esse mesmo movimento. A essência desse Théos que congrega em si a explicação do não-ser (do ser potencial) e do ser (do ser atual) permanece impensada, esquecida. Esquecimento que acaba por definir o pensamento metafísico como uma onto-teo-logia, cuja culminância acontece no pensamento tecnológico. Pois bem, Heidegger, ao se questionar sobre a essência do fundamento, a descobre não como a expressão da necessidade, mas da pura possibilidade - já que essa essência deverá explicar aquilo que fundamenta tanto o ser como o não-ser, cuja tensão se verifica no movimento de constituição de tudo o que é. Segundo Heidegger, o ser enquanto 
fundamento dos entes é, ele mesmo, sem fundamento. A essência do fundamento, aquilo que faz o fundamento ser isso que ele é, e como é, é, portanto, uma ausência (de fundamento). A essência do fundamento, ou numa outra formulação: o começo do começo é, pois, o abismo (Ab-grund), o nada (o poder-ser) cuja experiência é o salto.

O ser nunca pode primeiro ter um fundamento que o fundamente. $\mathrm{O}$ fundamento fica, desta maneira, afastado do ser. O fundamento fica ausente do ser. No sentido de uma tal ausência de fundamento de ser, o ser "é" sem fundamento (Ab-grund), abismo. Na medida em que o ser enquanto tal é fundamento em si mesmo, permanece ele mesmo, sem Fundamento (HEIDEGGER, 1983, p. 46).

O salto diz, precisamente, o estarmos jogados na experiência entre ser e fundamento, entre o ser (considerado em si mesmo) e o ser (considerado como fundamento) dos entes, entre ser e ente. No salto nos abandonamos àquilo a que pertencemos e que nos pertence, ou seja: nos abandonamos ao "comum-pertencer". No salto, o fundamento se mostra como fundamento e o ser como ser, é o limiar, o limite entre o ser e os entes. Limite no qual tudo o que é, começa a ser. O salto inaugura o jogo da existência, o jogo da criação do mundo. Segundo Leibniz, “enquanto Deus joga, o mundo se faz”. (LEIBNIZ apud HEIDEGGER, 1983, p. 241). Este salto nos remete para a própria experiência do sagrado, desde a qual os homens e os deuses se tornam presentes. Mas como podemos caracterizar o fenômeno do salto?

\section{V-Sobre o salto e a liberdade para o fundamento.}

Num pequeno conto, de aproximadamente dez páginas, intitulado Teatro de marionetes, o escritor prussiano Heinrich Von Kleist $(1777-1811)^{5}$ se serve da arte tão ordinária quanto secular das marionetes para tecer uma reflexão acerca da essência da existência humana. $\mathrm{O}$ ensaio consiste na conversa entre um famoso bailarino, o Senhor C., e o narrador, que permanece incógnito até o fim da sua narrativa. $\mathrm{O}$ encontro ocorre num teatro de marionetes lugar de espetáculo e de especulação. Desconcertado com o fato de tão famoso bailarino se deixar encantar por uma arte notoriamente burlesca, o nosso narrador põe-se a indagar o motivo de tanto interesse, pois não era a primeira vez que o via diante do palco das marionetes. O bailarino se põe, então, a falar-lhe da perfeição dos movimentos dos bonecos.

\footnotetext{
${ }^{5}$ Escritor que, segundo alguns críticos, talvez tenha servido de inspiração a Rainer M. Rilke para a composição da sua Quarta elegia à Duíno.
} 
Perfeição que se baseia na harmonia entre as mãos do titeriteiro e o centro de equilíbrio das marionetes. Perfeição que ele, enquanto bailarino, procura encontrar. Ao tomar ciência do tipo de interesse que leva o bailarino aos espetáculos de marionetes, o narrador se põe com ele a especular sobre o conhecimento extraordinário que parece mover o ordinário de determinadas ocupações humanas. O tipo de saber experienciado pelo titeriteiro, não cabe em nenhuma "explicação" da engenharia mecânica ou da física, não cabe em nenhum tipo de saber teórico. Os bonecos nada mais são do que "pêndulos mortos" que, por desconhecerem a lei da gravidade, se mostram totalmente obedientes ao toque das mãos que os manipulam. Mãos que, por sua vez, só sabem quando tencionar os fios, para manipular os títeres, à medida que destes mesmos fios se esquece, se unindo (neste esquecimento) ao boneco num mesmo movimento. Donde resulta a graça e a gratuidade dos gestos e movimentos do boneco. Tal gratuidade se expressa no modo como os bonecos integrados às mãos do titeriteiro se relacionam com o chão. Por se encontrarem aquém da lei de gravidade e do conhecimento trazido por essa lei, os bonecos se servem do chão apenas por um instante. "Os bonecos, como elfos, precisam do chão apenas para tocá-lo e reanimar o impulso de seus membros sobre esse obstáculo momentâneo. " (KLEIST, 1952, p.8.). A graça dos bonecos reside na gratuidade do impulso, do salto desde o qual nascem os seus movimentos. Salto que se origina da negação de si mesmo à medida que, para que o boneco retome os seus movimentos é preciso "tocar o chão", para nesse toque ganhar um ponto de "apoio" para um novo salto. Ao tocar novamente o chão, o salto anterior se nega, se retrai para que o novo salto se dê. Por conseguinte, é desde essa mesma negação (de si) que o salto novamente se instaura. Assim, esse salto em que o movimento se (re)instaura e que confere "vida" ao boneco, acontece à medida que para se dar o passo seguinte (no qual se instaura o novo salto) é preciso dar um passo atrás (no qual se retoma, numa negação, o salto anterior). O salto, no qual se integram num mesmo movimento o boneco e o titeriteiro, nasce da negação de si mesmo, e por essa mesma negação se mantém como tal. Por sua vez, nessa negação está em jogo o esquecimento de todo e qualquer saber teórico desde o qual nos é possível determinar a causa, o fundamento, a razão de ser do movimento que confere "vida" aos gestos do boneco e do titeriteiro.

Pois bem, o Senhor C. está em busca deste saber que se realiza quando o homem "esquece" das determinações que o fazem ser isto ou aquilo. Segundo esse bailarino, reter-se, permanecer preso à lembrança de um gesto ou movimento, faz com que alguns bailarinos célebres concentrem toda a alma num joelho ou cotovelo, tornando o movimento artificial. Isto se deve, consoante o bailarino, ao fato de o homem, ao comer da árvore do conhecimento, 
ter perdido a inocência responsável pelo esquecimento de si mesmo. Para recobrá-la seria preciso comer desta árvore uma segunda vez. E, deste modo, "escrever o último capítulo da História do mundo"( KLEIST, 1952, p. 13). Mas o que significa comer da árvore do conhecimento pela primeira vez?

Estar no paraíso é estar no estado de inocência. Estado este que se apresenta como a condição necessária para que se realize a experiência da liberdade - de poder ser ou não ser si mesmo. No estado de inocência há a experiência da liberdade, mas não um conhecimento efetivo dela: o homem simplesmente está em meio as suas possibilidades, como que delas esquecido. Esta experiência da liberdade, que acontece no estado de inocência, pode ser definida com Kierkegaard como o estado de angústia - que é introduzido no paraíso quando Deus proíbe a Adão de comer da árvore do bem e do mal. Esta proibição gera em Adão através das admoestações de Eva, que dele, Adão, descende - o desejo, a vontade de realizar, em si, este poder-ser. A angústia do homem é a angústia diante do nada, que é o puro possível, representado pela liberdade. No bojo desta angústia está à condição necessária para o pecado acontecer. Ou seja, a condição para que Adão desobedeça a Deus. A desobediência, a falta cometida implica na queda, na decadência do paraíso. O homem ao provar da árvore do conhecimento se vê compelido a sair do estado do puro possível, para o da efetividade. Vê-se compelido a saltar de um estado para o outro. Em Kierkegaard, esse salto se refere a uma mudança qualitativa do estado de inocência para o de pecado. Em o Conceito de angústia, o filósofo dinamarquês "define" o pecado pela noção de queda. O pecado é a queda, o cair ou decair de um estado para outro. Ou melhor, é a queda do estado de inocência para o de culpa. Ora, ser culpado significa ser responsável por, ser a causa de. Por inocência, o autor nos dá a compreender o estado de ignorância, no qual o homem se encontra imerso no nada, ou melhor, na pura possibilidade, no puro possível. Por conseguinte, a inocência seria o estado da pura indeterminação. por isso, tal estado de inocência nos remete invariavelmente para a angústia. Esta diz o estado no qual o homem possui uma compreensão afetiva e não intelectual deste estado de indeterminação. Ou seja, o homem, no estado de inocência é tomado pela angústia diante do puro possível no qual se encontra. Por outro lado, o pecado representa o momento em que o homem se vê, toma consciência deste seu estado. Ou melhor, se compreende como "falta", pois que enquanto puro possível, ele, em seu ser, encontra-se sempre em falta, carece sempre de realizar-se - como isto ou aquilo. Por isso, o pecado, mais do que se referir a uma ação qualquer, é o momento em que o homem se torna consciente da sua condição humana, que é a da liberdade compreendida como o puro possível. Sendo que 
esta "consciência", que caracteriza o pecado, devém, necessariamente, do estado de angústia não numa sequência linear, como uma consequência de um processo reflexivo, não como fruto de uma mediação, ou seja, de uma reflexão, mas como salto: de modo imediato. Por isso, o salto, a queda de um estado para o outro, não pode ser explicado de modo racional. O pecado surge, portanto, como coisa súbita, isto é, por meio de um salto; tal salto, contudo, instaura a qualidade; ora, a qualidade, sendo instaurada, implica e institui o salto. Tal como este a pressupõe e instaura. "Aí está o escândalo para a razão; portanto, tem de ser um mito. Em compensação, a razão mesma cria um mito que nega o salto e muda o círculo em uma linha reta, para que desse modo tudo se passe de modo natural" (KIERKEGAARD, 1968, p. 36).

Mas o que se quer compreender aqui por qualidade que é instaurada pelo salto? Segundo o verbete do dicionário de língua portuguesa qualidade é: “(...) a propriedade, atributo ou condição das coisas ou das pessoas capaz de distingui-las das outras e de lhes determinar a natureza. " (FERREIRA, 1986, p. 1424). Pois bem, no salto, no qual se dá o pecado é instaurada, é determinada a própria natureza humana; a natureza da nossa existência. Assim, nesta determinação, que advém com o pecado, nós nos compreendemos na nossa limitação, na nossa finitude face ao ilimitado, ao infinito de Deus. Por conseguinte, sair, cair, decair da inocência é sair do ilimitado, infinito e indeterminado da divindade. O pecado é, pois, o momento em que o homem compreende a si mesmo (em seu ser), ao se confrontar com Deus. Por isso, para Kierkegaard, o pecado é o fenômeno que garante a essência da individualidade; é "a categoria existencial por excelência" (KIERKEGAARD, 1968, p. 19). Desta forma, o indivíduo - o existente - é a síntese do eterno e do temporal. A existência é o ponto de encontro entre o finito e o infinito, que se opõem e se unem. Assim, o pecado original devém da angústia à medida que esta diz a sua própria origem. É na angústia, própria da inocência, que se origina o pecado. Segundo Kierkegaard, “(...) o profundo mistério da inocência é que ela é ao mesmo tempo angústia. No seu sonho, o espírito projeta a sua própria realidade; esta não é nada, mas este nada vê constantemente a inocência fora de si mesmo".( KIERKEGAARD, 1968, p. 19)

Da inocência para o pecado não há mediação, passagem reflexiva, mas salto. A estrutura da origem do pecado não se explica através de um tempo linear porque essa estrutura pressupõe o tempo de encontro entre o eterno e o finito, a que Kierkegaard chama de instante e que expressa no salto, no qual o indivíduo ganha a consciência da sua natureza ao se pôr em face de Deus. Por isso, o pecado traz implícito na sua estrutura, a própria redenção - porque 
nele Deus se faz presente em sua natureza eterna e infinita. Pois bem, no instante em que Adão come da árvore do conhecimento, ele saboreia o limite da sua existência. Contudo, Adão corre o risco de aí (nesse saber de si) permanecer, de permanecer na cristalização desse instante. É dessa permanência que nos fala o Senhor C. quando se refere ao ar "afetado" de determinados bailarinos que procuram reter o fluxo do movimento vital através de um conhecimento técnico qualquer. Mas o que ele compreende por comer dessa mesma árvore pela segunda vez?

Ora, comer da árvore do conhecimento pela segunda vez é perder esse conhecimento de si, é perder a determinação em que a individualidade se constitui. Contudo, essa perda não implica num "esquecimento" radical daquilo que se é. Essa perda consiste num retorno às possibilidades desde as quais, toda e qualquer determinação pode se dar. É fazer-se novamente inocente. Contudo, o que deverá retornar ao passado (à inocência perdida) é o presente que se traduz na decadência do pecado. Nesse retorno, o homem acaba por transcender essa decadência, ao reconduzi-la à sua origem. Nesse retorno o homem ganha um outro tipo de saber de si mesmo, ganha o saber da totalidade das suas possibilidades de ser. Saber do puro e simples poder-ser si mesmo. Saber que ao possuir por objeto o puro poder ser, se mostra como um saber que nada sabe (um não saber) e que se expressa na memória de ser, é desde essa memória que se movem as mãos do titeriteiro.

Assim, essa inocência reconquistada não se confunde com o estado primitivo da inocência no qual o homem possui o saber de si mesmo de um modo indeterminado - o "possui" como quem é possuído por um sonho -; tampouco se deixa tomar pelo estado de pecado, no qual o homem salta dessa indeterminação da inocência para a sua singularidade. A inocência adquirida quando o homem come da árvore do conhecimento pela segunda vez é aquela que congrega em si esses dois momentos e, no entanto, não se deixa determinar por nenhum deles. É a experiência de estar entre dois, entre o sim e o não, entre a mão e o boneco. Ou seja, é a experiência do fio da marionete que une e separa a mão do titeriteiro - mão que representa a experiência da singularidade adquirida pela queda, pelo pecado original - e o boneco - que representa o estado primitivo da inocência. $\mathrm{O}$ fio nos permite compreender a tensão que se estabelece entre esses dois estados. Tensão na qual é continuamente reinstaurado o movimento desde o qual o mundo vem a ser. Ou seja, é na tensão e retenção do fio que acontece o espetáculo; é onde se dá o sentido tanto do manipulador quanto da marionete. É no fio que ambos vêm a ser; sendo aquilo que a um só tempo os une e separa enquanto o espaço da diferença que possibilita o modo de ser de cada um. Também é o que gera o movimento em 
que dois se acham integrados como um só. O fio é a experiência mesma do salto (enquanto esse se expressa desde a negação, a retração de si mesmo) no qual esses dois estados, da inocência e do pecado, retornam um sobre o outro. É desse fio que nos fala Nietzsche, ao nos falar da condição da existência humana:

O homem é uma corda estendida entre o animal e o super-homem - uma corda sobre um abismo. É o perigo de transpô-lo, o perigo de estar a caminho, o perigo de olhar para atrás, o perigo de tremer e parar. O que há de grande no homem, é ser ponte, e não meta: o que pode amar-se no homem, é ser uma transição e um ocaso. (NIETZSCHE, F., 1989, p.31).

\section{Concluindo}

Pois bem, Heidegger retoma a experiência do salto presente no pensamento de Kierkegaard, contudo, ele, diferentemente de Kierkegaard, pensa o instante de acontecimento deste salto vinculado ao porvir, ${ }^{6}$ o que faz com que esse salto se dê sempre como uma negação de si mesmo, instaurando nessa negação um movimento de retorno sobre si mesmo. Retorno expresso no ensaio de Kleist pelo saborear (pelo saber) pela segunda vez da árvore do conhecimento. Retorno que libera a memória do ser. Memória em que se traduz o pensamento que, para Heidegger, ainda está porvir:

Um tal pensamento não é nem teórico nem prático. É antes dessa distinção do teórico e do prático que ele se apropria. Na medida em que ele é ele mesmo, um tal pensamento não é senão memória (Andenken) do ser e nada mais. Pertencendo ao ser, por ter sido lançado pelo ser na guarda e proteção de sua verdade e assim para ele requisitado. Pensa ele o ser. Um tal pensar não dá resultado. Não tem efeito. Ele se basta à sua Essência, sendo. Ora, ele é, dizendo a sua causa (Sache). À causa do pensamento pertence, e sempre historicamente, um só dizer, o dizer de acordo com a essência de sua causa. Cuja constringência, por se ater à sua causa, é essencialmente superior à validade das ciências, por ser mais livre. Pois ele deixa o ser ser ( HEIDEGGER, M., 1967, p. 90).

Essa memória do ser (Andenken) traduz a própria essência do pensamento que tudo mede e calcula. Ou seja, a memória do ser é o fenômeno em que o pensamento da era da técnica “vigora, desenvolvendo a força do seu vigor"(CARNEIRO, 1967, P. 23) como o esquecimento desse mesmo ser. Heidegger concebe a memória do ser como a experiência de resguardo da história do povo ocidental. Enquanto esse resguardo, o pensamento assim compreendido, não é teórico nem prático à medida que se deixa ser tanto um como outro modo de ser. Ou seja, a memória do ser deixa ser tanto o pensamento teórico - cuja plenitude

\footnotetext{
${ }^{6}$ Cf. HEIDEGGER, M., 1989, p. 135, nota, 69
} 
se expressa no modo de ser que regula todo comportamento que o homem estabelece com o mundo através do cálculo e da medida - quanto prático, cujo modo de ser que regula nosso comportamento através do trabalho. Enquanto a condição de possibilidade desses tipos de pensamento, a memória do ser não se confunde com nenhum deles. Ou seja, no resguardo da história ocidental, a memória do ser acaba por superar todas as oposições de pensamento que se verificam ao longo dessa história. Porém, tal superação não se confunde com o movimento que se verifica no interior da dialética hegeliana, na qual as oposições são suprassumidas numa nova síntese - que deverá abrir uma nova época do pensamento, ou numa linguagem hegeliana, uma nova figura da consciência. No pensamento de Heidegger o termo superação assume o sentido mais profundo de liberdade, ou seja, superar significa aqui: deixar ser o sim e o não já sempre presentes no pensamento ocidental. Liberdade para o fundamento. Liberdade inaugurada no salto sob o abismo do ser no qual se dimensiona a experiência do sagrado. Tal experiência deixa entrever o que existe de mais próprio no acontecimento do ser que é o caráter da mais pura gratuidade. Tal experiência compreendida como o salto, que nasce desde si mesmo e que em si mesmo se mantém, revela o modo como, cotidianamente, o sagrado se revela como a dinâmica que impulsiona, promove e mantém a nossa existência no tempo e como tempo. O sagrado se revela, então, como o extraordinário que se retrai, que declina a cada vez que nos havemos no tempo; a cada vez que nos ocupamos no mundo - se retrai no indiferenciado dos nossos dias; declina e se oculta nos gestos das nossas mãos. Talvez, por isto o poeta nos diga:

Todos os que movimentam as mãos \não no tempo, mas na cidade pobre; \odos os que põem as mãos de leve $\backslash$ n'algum lugar, distante dos caminhos, $\backslash$ e mal chegam ainda a ter um nome:\Todos falam de ti, benção diurna, \e de uma folha com doçura dizem $\backslash \mathrm{O}$ que no fundo existe é apenas prece, $\backslash$ e assim as mãos que nos são consagradas $\backslash$ coisa alguma criam que não implore; \se antes alguma pintava ou ceifava, $\backslash$ já na circunscrição das ferramentas $\backslash$ era a devoção que se desdobrava. \O tempo é uma mão de muitas formas. \Muitas vezes no tempo nós ouvimos o antigo e o eterno se fazendo; \e sabemos que um deus nos envolvia. (RILKE,1993, p.58).

É desde essa experiência que o pensar se instaura. Não apenas o pensar que tudo mede e calcula, mas, também e igualmente, o pensar como a pura e simples meditação sobre o tempo que nos constitui como homens em nossa morada sobre a terra; que nos constitui na nossa pobreza e indigência face ao puro possível que nos constitui e que temos sempre que realizar; e, diante do qual estamos sempre em falta, em débito. É na experiência radical dessa pobreza, que se mantém em cada ação nossa no tempo, que o sagrado se revela. 


\section{REFERÊNCIAS BIBLIOGRÁFICAS}

BIRAULT, H.. Heidegger et l'expérience de la pensée. Paris: Gallimard, 1978.

FERREIRA, A., B., H. Novo Dicionário da Língua Portuguesa. Rio de Janeiro, 1986.

FOGEL, G.; Hans, R.; SCHUBACK, M. C. Por uma fenomenologia do silêncio. Rio de Janeiro: Sette Letras, 1996.

HEIDEGGER, M. Acheminement vers la parole. Paris: Gallimard: 1976. . Introduction à la métaphysique. Paris: Gallimard, 1980. La fin de la philosophie et la tâche de la pensé. Paris: Gallimard,1980 . La question de la technique. Paris: Gallimard,1980. . Le principe de raison. Paris: Gallimard,1983. . L'être, le fund et le jeu. Paris: Gallimard,1983.

. L'Experiénce de la pensée .In: Questios III. Paris: Gallimard, 1976. . Pour servir de commentaire à serénité. Paris: Gallimard,1976.

.Qu'appelle-t-on penser?. Paris: Gallimard, 1976.

. Questions IV. Paris: Gallimard,1980.

. Science et méditation.Paris: Gallimard, 1980.

. Sérénite. Paris: Gallimard, 1976.

. Ser e Tempo. Petrópolis: Vozes, 1989.

. Sobre a essência do fundamento. Lisboa: Edições 70, 1988 .

. L'Époque des conceptions du monde. In: Chemins qui ne Ménent nulle part. Paris: Gallimard, 1980.

. Sobre o Humanismo. Introdução e notas de Emmanuel Carneiro Leão. Rio de Janeiro: Tempo Brasileiro, 1967.

Cultural, 1978.

. O que é isto - A filosofia? Tradução de Ernildo Stein. São Paulo: Abril . Sobre a essência do fundamento. Lisboa: Edições 70, 1988.

KIERKEGAARD, Soren. O Conceito de angústia. Tradução de Torrieri Guimarães. São Paulo: Hemus, 1968.

KLEIST, Heinrich Von. Teatro de marionetes. Rio de Janeiro: Serviço de Documentação do Ministério da Educação e Saúde, 1952.

NIETZSCHE, F. Assim falou Zaratustra, Tradução de Mário da Silva. Rio de Janeiro: Ed. Bertrand do Brasil S.A, 1989

NUNES, B., Passagem para o poético. Filosofia e poesia em Heidegger. São Paulo: Ática, 1986.

LANDIM, R., Evidência e Verdade no Sistema Cartesiano. São Paulo: Editora Loyola, 1992.

RAVEN, J. E., Os filósofos pré-socráticos. Tradução de Carlos Alberto Louro Fonseca, Beatriz Rodrigues Barbosa e Maria Adelaide Pegado. Lisboa: Fundação Calouste Gulbenkian, 1982.

RILKE, R. M. Livro de Horas. Rio de Janeiro: GEIR, 1993. 